\title{
Building Fire Impact Model
}

\author{
$\underline{\text { Sanabria L.A. }}{ }^{\mathrm{a}, \mathrm{b}}$, French I. ${ }^{\mathrm{a}, \mathrm{b}}$ and Cechet R.P. ${ }^{\mathrm{a}, \mathrm{b}}$ \\ ${ }^{a}$ Environmental Geoscience Division, Geoscience Australia, Canberra ACT \\ ${ }^{b}$ Bushfire Cooperative Research Centre, Melbourne Australia. \\ Email: augusto.sanabria@ga.gov.au
}

\begin{abstract}
The aim of the Building Fire Impact Model (BFIM) is to study the impact of human intervention in a bushfire situation, focusing on the peri-urban communities. The model resides within the Fire Impact and Risk Evaluation Decision Support Tool (FireDST) which simulates fire conditions (Bushfire CRC, 2013). The BFIM recognises that occupants can prepare their house to withstand a bushfire, and if such an event occurs, they can defend their house and may reduce total house loss in the bushfire. To take into account the large uncertainties associated with human intervention, the BFIM was designed to be a probabilistic model, i.e. it uses random variables to represent the main characteristics of occupant intervention. To deal with the complexity of such a model, a mathematical technique called Probabilistic Event Trees (PET) is utilised. In this technique events are represented by the nodes of a mathematical tree and the probability of these events occurring are the tree branches. The conditional dependency of variables is represented by their relative location in the tree.
\end{abstract}

The BFIM consists of two PETs. The first PET simulates occupant intervention to defend their house from ember attack and possible help from neighbours and the rural fire brigade. The ability of occupants to defend a house depends on their preparation and the preparation of the house to withstand the fire. Occupant preparation comprises purchase of fire-fighting equipment, undergoing training, conducting regular drills, development of an evacuation plan, etc. House preparation involves activities such as cleaning gutters, cutting trees and grass surrounding the house, etc. A series of occupant characteristics are used to assess their efficiency in fighting the ember attack. This tree also calculates the impact of wind speed on the house. Houses damaged by wind/debris during the fire have a higher probability of being ignited by an ember attack.

The second PET calculates the impact of radiation in 'house-to-house' fire spread. This tree examines the impact that houses ignited in the first PET have on nearby houses. The main variables to consider in this part of the model are wind damage to a house, proximity of a house to a neighbouring ignited house and the number of neighbouring houses burnt by the bushfire. An important problem also considered in this tree is 'smoldering embers' - embers that penetrate the house through the roof and slowly burn flammable material due to lack of oxygen - which can results in house loss long after the fire front has passed through the region. Wind and wind damage to the roof increase the danger from this type of ember attack process.

To simulate the dynamic characteristics of these issues, the two PETs are solved sequentially: results of the first PET are used to set up the correct fire conditions for solution of the second PET. For this reason the FireDST simulation model is run three times (passes) for a region. In the first pass, the model calculates the fire conditions in the region of interest and returns the number and location of houses potentially impacted by the fire. In the second pass, the first tree of the BFIM is solved to calculate the impact of human intervention. This sets up different fire conditions and hence FireDST recalculates the number of houses burnt under the new conditions. In the third pass, the second tree of the BFIM is solved to assess house-to-house fire spread. Some houses with a high probability of being 'saved' in the second pass can be reclassified as having a high probability of being 'burnt' after the third pass has been completed.

To illustrate the model, an example case based on the Kilmore bushfire that occurred on 'Black Saturday' (7 February 2009) is provided. Results show that human intervention to fight the fire threatening a house can make a substantial difference to the number of houses burnt.

Keywords: Bushfire risk, fire spread, ember attack, suppression, human intervention. 


\section{INTRODUCTION}

The Fire Impact and Risk Evaluation Decision Support Tool (FireDST) is a multi-disciplinary and multiagency project funded by the Bushfire Cooperative Research Centre. It has developed a 'proof of concept' simulation system and corresponding software to study the potential impact a bushfire may have on community assets, infrastructure and people. FireDST integrates, within a probabilistic framework, a number of complex models (French et al., 2013). The Building Fire Impact Model (BFIM) is one of the core models in this framework.

BFIM simulates the impact of human intervention on the defence of houses threatened by embers and the impact of radiation from neighbouring houses. As there is a large variation and uncertainty associated with human intervention in fighting a bushfire attack on a house the main variables of BFIM are represented by random variables. BFIM is therefore a probabilistic model using a mathematical technique called a Probabilistic Event Tree (PET). In this technique, events are represented by the nodes of a mathematical tree and the probability of these events occurring is the tree branches. The conditional dependency of variables is represented by their relative location in the tree (Hasofer et al., 2007). These probabilities can be calculated from statistics of forest fires, from simulations or from experts in the field who can allocate probabilities heuristically.

In some applications it is necessary to use dynamic trees. These types of trees are used to represent the interaction between the different variables (Zhao and Beck 1997). Within FireDST house loss from a bushfire in the region of interest is calculated without taking into account human intervention. Once human intervention is taken into account there is a new set of conditions; occupants can substantially modify the bushfire outcome rendering invalid the initial set of fire conditions considered. To represent this characteristic of the problem, dynamic event trees have to be used. These types of trees are implemented by solving sequentially two PETs: the first PET modifies the impact of the fire on the built environment by taking into account human suppression. This information is sent back to FireDST for a recalculation of the fire impact on the built environment. Once the new conditions are established, a second PET is solved to calculate house-to-house fire spread through flame and radiation.

To capture this dynamic interaction between models, FireDST is run three times. In the first pass, the model calculates the fire conditions in the region of interest and returns the number of houses burnt and ember density and radiation faced by each house. In the second pass, the first tree of the BFIM is solved to calculate the impact of human intervention. This pass sets up different fire conditions; FireDST is run again to recalculate the number of houses burnt and then the third pass is run. In the third pass, the second tree of the BFIM is solved to assess house-to-house fire spread. Figure 1 shows the interaction between FireDST and the two PETs of BFIM.
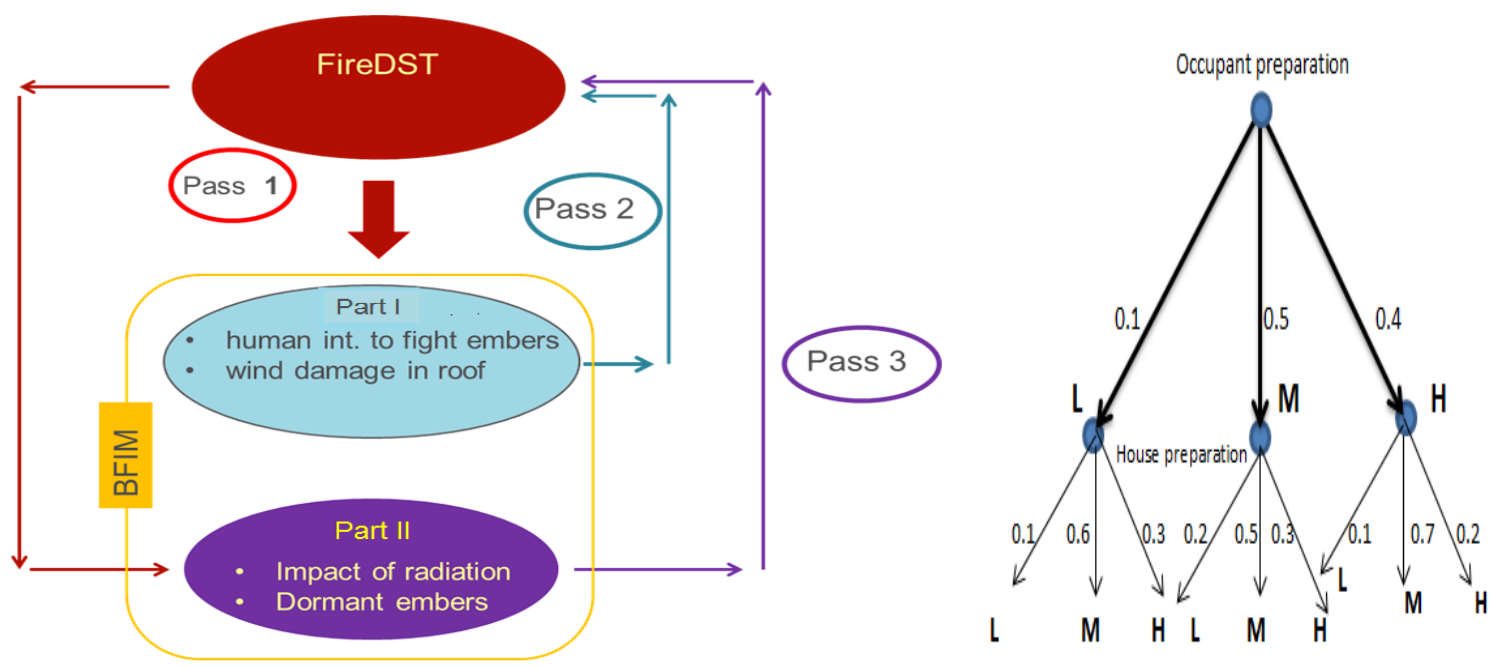

Figure 1. Interaction between FireDST and BFIM.

Figure 2. Occupants' effectiveness tree. 


\section{MODEL DESCRIPTION}

\subsection{Part I: Human intervention}

The first part of BFIM simulates occupants fighting the ember attack to defend their house with possible help from neighbours and the rural fire brigade. Human intervention can only happen if the radiation affecting the house is less than a threshold. This threshold is estimated to be $2 \mathrm{kWatts} / \mathrm{m}^{2}$ for occupants and neighbours; and $4 \mathrm{kWatts} / \mathrm{m}^{2}$ for fire-fighters with protective clothing (Raj, 2008). The ability of the occupants to defend a house depends on their preparation and the preparation of the house to withstand the fire. BFIM uses Geoscience Australia's National Exposure Information System (NEXIS) database to provide house location and characteristics (Nadimpalli, 2009; Canterford, 2011). The number of occupants and their attributes per house was generated for this project based on SA1-level Australian Bureau of Statistics (ABS) 2011 Census data (ABS, 2012). The number of people in a SA1 was divided by the number of houses in the same SA1 to develop the occupant characteristics. These characteristics are used to assess their efficiency with regards to fighting ember attack.

The first step in the calculation is to determine whether the occupants are available to fight an ember attack. The analysis is carried out house by house. The model recognises that not every occupant can join the emberfighting activity; people who are too young or too old are not included in the fire-fighting activity. Currently the threshold we use for these limits are 5 and 65 years old. These parameters are entered through external files to allow users flexibility to change them. The model also recognises that the number of occupants at home during normal working hours may be less than the number of house occupants. Brenan et al. (1998) suggests that only 10 percent of occupants can be found at home during normal working hours and 70 percent during non-working hours. The total number of occupants available to fight the ember attack is given by:

$$
N a=p_{-} \text {number } * \text { age } \text { factor }^{*} \text { type _of _day }
$$

where 'p_number' = house occupants, 'age_factor' indicates the percentage of people between 5 and 65 years old, 'type of day' indicates whether the fire occurs on a normal working day.

Once the number of occupants able to fight the fire has been established, the model then assesses how effective these occupants are in the fight against an ember attack. Occupant effectiveness is a complex function of training, equipment available to fight embers, type of community, level of education, whether the occupants can understand English (and hence listen to radio warnings or advice), whether they are volunteers in their community, and the number of years they have lived in the area (Dwyer et al., 2004; Solangaarachchi et al., 2012). Occupants who are well prepared, i.e. occupants who are available to fight the fire, who are proficient in English, who have finished year 12, who don't need assistance, who are volunteers in their community and who have been living in the area for a minimum of 5 years, will be assigned an 'occupant preparation' of H(igh). Figure 2 shows a typical effectiveness PET. The probability associated with the first branch of this PET indicates that 40 percent of occupants in the simulation region can be classified as 'highly prepared' while only 10 percent can be classified as low or not prepared at all.

Similarly, the house preparation is a complex function of gutter status, house age, the condition of the vegetation and grass surrounding the house (garden) and so on (McLennan et al., 2011). Some of these variables can be obtained from remote sensing and rural fire service and council inspections. The second branch of Figure 2 considers three possibilities for house preparation: L(ow), M(edium) and H(igh). The user can allocate probabilities to each option to reflect his/her understanding of house preparation in the region under study. The model also recognises that, in some cases, neighbours can help occupants with their emberfighting effort. In this study neighbours are those occupants available to fight the ember attack who live within a $100 \mathrm{~m}$ radius. The number of neighbours helping the occupants depends on proximity to the occupants' house, access to the house, and familiarity with the neighbour and his/her surroundings. The actual number of neighbours who come to help $(\mathrm{Nb})$ is a proportion of all available neighbours; this proportion is given by variable 'neighb_pc'. In this study this variable is set to 25 percent. Solution of the PET of Fig. 2 gives occupants' efficiency probability ('eff_prob').

The efficiency of ' $\mathrm{Na}$ ' occupants and ' $\mathrm{Nb}$ ' neighbours fighting the ember attack is given by:

Tot_eff $(\%)=100 *\left(N a *\right.$ eff_p prob $+0.75 * N b^{*}$ neighb_pc ${ }^{*}$ eff__prob $)$

Note that neighbours' efficiency is only 75 percent of the occupants' efficiency on account of their lack of familiarity with the house environment and the fact that they will also be keeping an eye on their own property. To simulate occupant and neighbour suppression, the ember density attacking the house is reduced by the percentage given by 'Tot_eff'. 
The Human Intervention module also considers ember suppression by fire services, including volunteer and professional rural fire fighting organisations. The first element we have to consider is whether the unit (fire truck, tender, ute with tank/pump etc.) can attend at the house. The total number of houses attended by a fire unit during a fire event depends on the number of units available (num trucks), the mean time for each attendance in the zone (time_per_visit), and the number of hours the fire has been active in the zone (hours_fire), that is:

$$
\text { num_visits }=(\text { num _trucks } * \text { hours _ fire }) / \text { time _ per_visit }
$$

Next we randomly allocate the number of visits calculated in (3) to the same number of houses, usually a small subset of houses, in the region of interest. The fire services or fire brigade (FB) efficiency in fighting the ember attack depends on a number of factors; house preparation, occupant preparation, house type, time after fire started, ember density, FB resources, etc. If there are a high number of occupants and neighbours fighting the ember attack, we assume that the FB efficiency is very high and allocate a value of 90 percent to FB efficiency; this value is reduced in proportion to the number of people fighting the embers at the site. To simulate FB suppression, the ember density attacking the house is reduced by the 'FB efficiency' percentage.

\subsection{Wind damage}

The human intervention module also recognises that wind damage to a house may make the house more vulnerable to ember attack. Openings in a house's envelope sufficient to admit embers can be caused by impact by debris with sufficient momentum to pierce the part of the house envelope, or cause mechanical failure of part of the house envelope. As a starting point for this module, Figure 3 shows a fragility curve for a typical house in Western Sydney. This curve was used to estimate of the probability that wind creates an opening in the house's envelope sufficient to admit embers. A house can have more than one opening but the curve represents the probability of a dominant opening occurring which needs not be large. A single opening would be sufficient to admit embers into the house (Cyclone Testing Station, 2008).

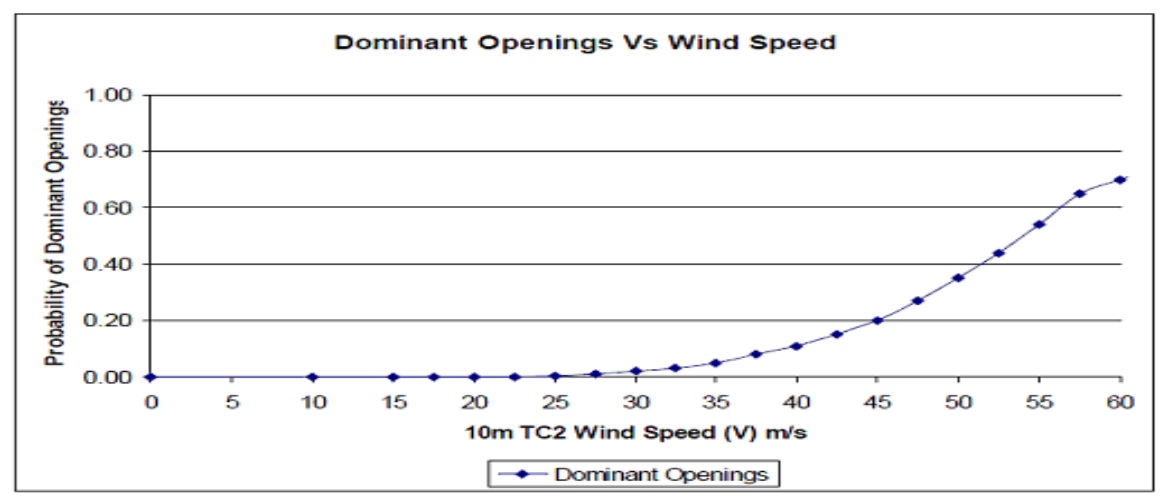

Figure 3. Probability that a wind speed causes an opening in a house.

The wind gust speed associated with that low probability would be sufficient to propagate debris with the capacity to pierce the house's envelope. The site gust wind speed threshold 'for openings' has initially been set to $28 \mathrm{~m} / \mathrm{s}$ (lower limit) corresponding to a probability of 0.02 . For values of wind speed less than or equal to $28 \mathrm{~m} / \mathrm{s}$ the probability of house damage is very low. It is assumed that values of wind speed greater than 28 $\mathrm{m} / \mathrm{s}$ produce openings in the roof and other parts of the house where it is easy for embers to enter the house; we simulate this by increasing the ember density affecting the house in proportion to the wind speed.

\subsection{Part II: House to house fire spread by radiation}

In this module we consider the impact that a burning house has on its neighbouring houses. We consider houses that are closer (in absolute distance) than $120 \mathrm{~m}$ to our target house. Whether or not a house is burnt by their neighbouring house(s) depends on four factors:

- whether the target house has already been damaged by wind or debris;

- proximity of the target house to a neighbouring house which is in flames;

- number of fire fronts facing the target house; and

- whether the house is protected by neighbouring buildings not impacted by the fire.

Houses further than $120 \mathrm{~m}$ away have very low probability of impacting the target house as explained below. Figure 4 shows the corresponding PET for this part of the BFIM (due to space considerations only one tree 
per branch is shown). The first variable considered in this part of the model is wind damage (WD). If the windows or doors of a house have been damaged by wind it is more likely that flames can penetrate the house. The actual level of damage to the house can be assessed based on Figure 4. The first tree of Figure 4 shows that a house with high wind damage $(\mathrm{H})$ has a higher probability of being burnt. The second tree (house proximity - HP) considers the distance of the target house to a house which has been impacted by the fire. If this distance is less than $60 \mathrm{~m}$ the probability that the target house is burnt is high, and we allocate a value of 0.9 to branch $(\mathrm{H})$. If it is more than $120 \mathrm{~m}$ the probability is low and we allocate a value of 0.01 and so on.

The next tree (fire fronts - FF) considers the number of neighbouring houses impacted by the fire. Obviously if there are more than two neighbouring houses burning, the probability that our target house is burnt is high (H) so we allocate a value of 0.7 to this event. If there are two houses burning in the neighbourhood, the probability must be lower, so we allocate a value of 0.2 to this event and so on. The last tree (shielding factor - SF) refers to the number of neighbouring houses not impacted by the fire which can act as a barrier to the fire reaching the target house; this is called the 'shielding factor'. The greater the number of houses not on fire between the target house and the houses burnt by the fire, the lower the probability that the target house is impacted by the fire. This event is represented by the $\mathrm{H}$ branch (high shielding factor) with probability of 0.1 . The opposite is represented by branch $\mathrm{L}$ with a high probability, i.e. if the shielding factor provided by neighbouring houses, not in flames, is low, the probability that our target house burns is high.

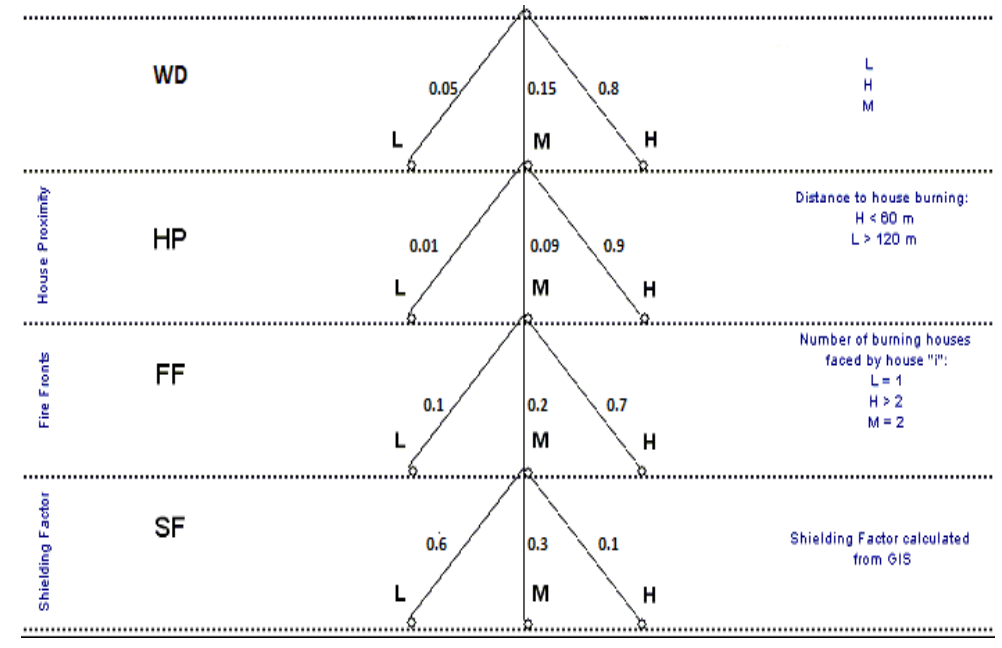

Figure 4. PET for fire spread through radiation

Solution of the PET shown in Figure 4 estimates the probability that the target house is burnt by the bushfire. As an illustration consider the case of a target house damaged by high wind, which is closer than $60 \mathrm{~m}$ to a house in flames, which is surrounded by more than two houses in flames and that it has a low shielding factor. The probability that this house is destroyed by the fire is given by the multiplication of all " $\mathrm{H}$ " branches of the four trees.

The last part of this Section considers the impact of 'dormant embers' on houses. In many fire events, houses can be burnt by embers hidden in cavities in the house roof. These embers can be activated by wind or flammable material in close proximity, and can ignite the house long after the fire has passed through the region. The modelled probability that a house is burnt by smoldering embers depends on four events:

- the house has been affected by wind speeds greater than $28 \mathrm{~m} / \mathrm{s}$ as explained in Section 2.2;

- during the fire the house has been subjected to embers with a density greater than a given threshold, currently estimated to be one third of maximum ember density in the region of interest;

- The combined efficiency of occupants and neighbours is lower than a given threshold, currently at 25 percent (See (2)); and

- the house has not been visited by the fire services (see Section 2.1).

The rationale for the two last events is that ill prepared occupants and neighbours may not be aware of the smoldering ember problem and will fail to examine the roof after the fire has passed through the region. On the other hand, if the house has been visited by the fire brigade, it is assumed that the fire fighters will look in roof cavities and will extinguish smoldering embers if they are found. 


\section{CASE STUDY EXAMPLE}

To illustrate the model, an example case based on Kinglake West bushfire of 'Black Saturday' (7 February 2009 ) is discussed. The layout of houses (297) in the region of interest is shown in Figure 5. Table 1 shows the impact of the fire considering the different parts of the model. The columns show the number of houses destroyed and the rows are the different parts of the BFIM model presented in this paper.

Table 1. Step by step account of the BFIM simulation results with FireDST.

\begin{tabular}{|c|c|c|c|c|c|c|c|}
\hline \multirow[t]{2}{*}{ BFIM Stage } & \multirow[t]{2}{*}{$\begin{array}{l}\text { Houses } \\
\text { destroyed } \\
\text { by embers }\end{array}$} & \multirow[t]{2}{*}{$\begin{array}{l}\text { Houses } \\
\text { destroyed } \\
\text { by } \\
\text { radiation }\end{array}$} & \multicolumn{3}{|c|}{$\begin{array}{l}\text { Number of houses } \\
\text { destroyed in house-to- } \\
\text { house fire spread with } \\
\text { corresponding prob. }\end{array}$} & \multirow[t]{2}{*}{$\begin{array}{l}\text { Total } \\
\text { houses } \\
\text { destroyed }\end{array}$} & \multirow[t]{2}{*}{$\begin{array}{l}\text { Percentage } \\
\text { of total } \\
\text { houses }\end{array}$} \\
\hline & & & $100 \%$ & $90 \%$ & $80 \%$ & & \\
\hline $\begin{array}{l}\text { Initial conditions from } \\
\text { FireDST }\end{array}$ & 28 & $\mathrm{n} / \mathrm{a}$ & $\mathrm{n} / \mathrm{a}$ & $\mathrm{n} / \mathrm{a}$ & $\mathrm{n} / \mathrm{a}$ & 28 & 9.4 \\
\hline $\begin{array}{l}\text { BFIM Pass } 1 \\
\text { (Human Intervention) }\end{array}$ & 3 & $\mathrm{n} / \mathrm{a}$ & $\mathrm{n} / \mathrm{a}$ & $\mathrm{n} / \mathrm{a}$ & $\mathrm{n} / \mathrm{a}$ & 3 & 1.0 \\
\hline (FireDST $2^{\text {nd }}$ Pass) & 3 & 50 & $\mathrm{n} / \mathrm{a}$ & $\mathrm{n} / \mathrm{a}$ & $\mathrm{n} / \mathrm{a}$ & 53 & 17.9 \\
\hline $\begin{array}{l}\text { BFIM Pass2 } \\
\text { (house to house spread) }\end{array}$ & 3 & 50 & 27 & 3 & 3 & 86 & 29.0 \\
\hline
\end{tabular}

FireDST provides the initial conditions for BFIM (see Figure 1). These initial conditions are given in the first row of Table 1: there are 28 houses destroyed by the ember attack, representing a 9.4\% of houses in the region of interest. The first part of BFIM simulates human intervention and the results of this part of the simulation are presented in row two: there are now only three houses burnt by the ember attack, representing more than 9 times improvement. It demonstrates the importance of human intervention in a fire simulation model. This is supported by the study of Blanchi and Leonard (2008) in which they examined post-event bushfire impact survey information. They concluded that houses had between 3.8 and 7.5 times greater chance of being destroyed if no one was present.

In the second part of the model we consider the impact of radiation. Row three shows the initial conditions calculated by FireDST. There are now 50 houses destroyed by radiation, so the total number of houses lost is 53. Results of the second part of BFIM (Section 2.3) are shown in row four with 33 houses $(27+3+3)$ marked with very high probability $(80-100 \%)$ of being burnt by house-to-house fire spread. The total number of houses likely to be destroyed by the fire is now 86 representing a total of 29 percent of houses loss out of the 297 houses in the region of interest. Figure 5 summarises the results.

The model has been developed in a modular fashion to allow the inclusion of more variables into it if necessary. Currently we are conducting large scale sensitivity analysis in order to assess the relevance of the variables used in the present model. Once the model has been calibrated we will be able to compare our results against known bushfire events.

\section{CONCLUSIONS}

We have presented a basic probabilistic model to study the impact of human intervention on bushfires within a peri-urban community. The model considers a number of variables including house loss due to wind damage, house-to-house fire spread due to radiation, the effect of smoldering embers; and human suppression. Preliminary results show that human suppression is a very important variable in house survivability; it can make a significant difference in terms of house loss. The efficiency of the human suppression, however, depends on occupant preparation as well as house preparation.

\section{FUTURE WORK}

The BFIM has been run in scenario (deterministic) mode to develop the model and to test the sensitivity of the input parameters on the output. We plan to conduct Markov Chain Monte-Carlo (MCMC) runs to determine the appropriate model parameters by comparing against known fire events and also gain a better understanding of the most important elements of a human suppression model. 


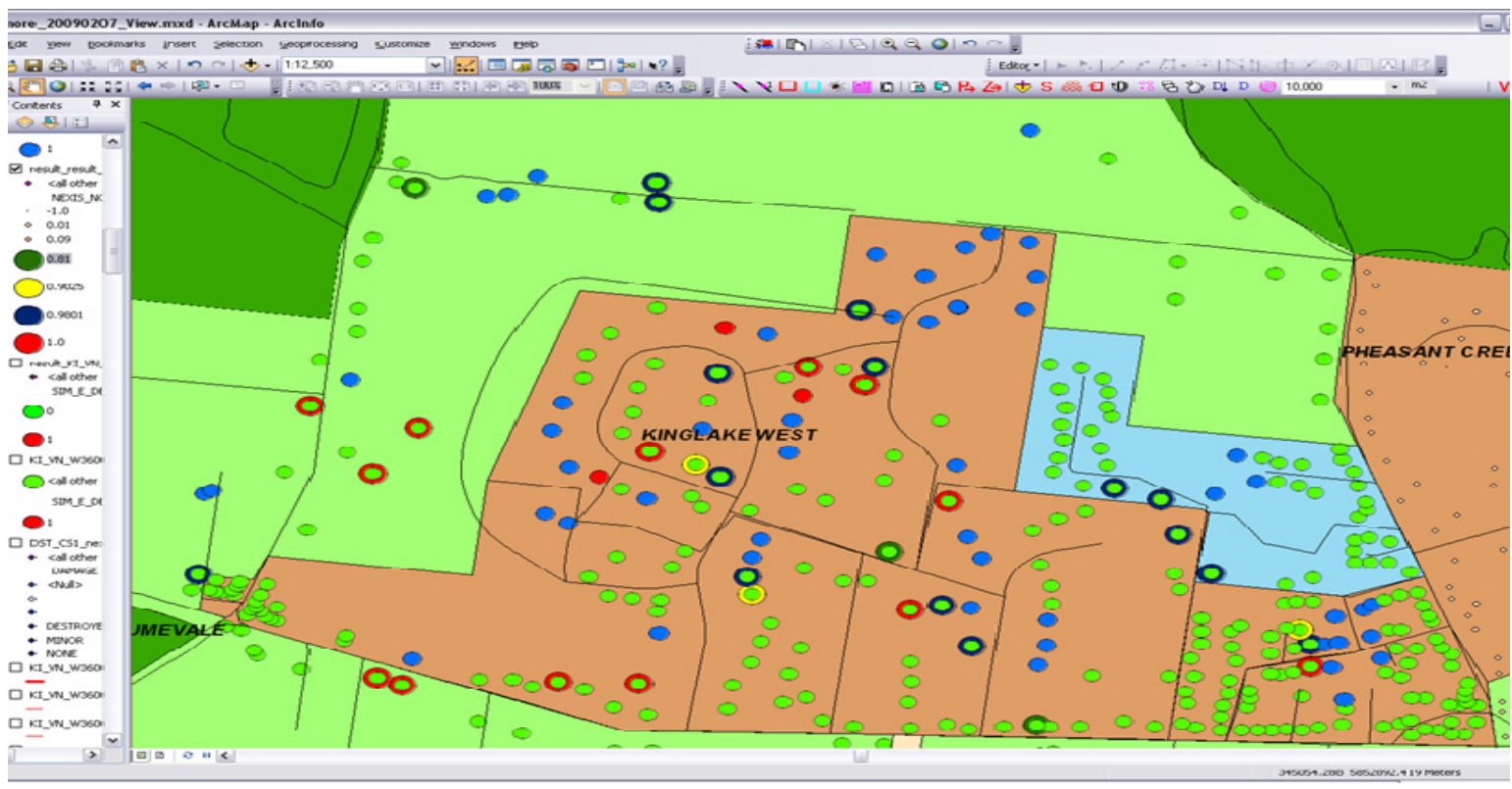

Figure 5. Example fire simulation. Green dots are houses not affected by the fire. Red dots indicate houses burnt by embers (BFIM pass 1, human intervention). Green dots with the red circle are houses burnt by radiation (BFIM pass 2). Blue dots are houses burnt by radiation in FireDST simulation (initial conditions). Green dots with the black circle are houses with 80 percent probability of being burnt by radiation. Green dots with the yellow circle indicate houses with 60 percent probability of being burnt by radiation.

\section{REFERENCES}

ABS (2012). 2011 Census of Population and Housing. Catalogue 2001.0, Second Release, Australian Bureau of Statistics, Canberra.

Blanchi, R., and Leonard, J. (2008). The influence of human behavior on house loss, AFAC/BCRC conference, http://www.bushfirecrc.com/managed/resource/dblanchi.pdf, accessed in July 2013.

Brennan, P., Doughty B., Horasan, M., and Li, S. (1998). Human Behaviour Model. Fire Code Reform Centre Project 4, CESARE Report, Victoria University, Melbourne, March 1998.

Bushfire CRC (2013). Fire Note. Issue 109. May 2013. http://www.bushfirecrc.com/resources/firenote/fire-impact-andrisk-evaluation, accessed in July 2013.

Canterford, S. (2011). Locating People Spatially: 2006, 2010, 2100 and 2:36PM on Friday, Australasian Journal of Regional Studies, (17) 1, 46-59

Cyclone Testing Station (2008). Estimate of Wind Damage to Contemporary West Sydney Houses, CTS Research Report: TS704. Report to Geoscience Australia, James Cook University.

Dwyer, A., Zoppou, C., Nielsen, O., Day, S., and Roberts, S. (2004). Quantifying Social Vulnerability: A methodology for identifying those at risk to natural hazard. Geoscience Australia Record 2004/14. GeoCat \# 61168.

French, I., Cechet, R.P., Yang, T., and Sanabria, L.A. (2013). FireDST: Fire Impact and Risk Evaluation Decision Support Tool. Paper submitted to the $20^{\text {th }}$ Int. Congress on Modelling and Simulation (MODSIM2013). Adelaide, Dec. 1-6, 2013.

Hasofer, A.M., Beck, V.R., and Bennets, I.D. (2007). Risk Analysis in Building Fire Safety Engineering. Elsevier.

McLennan, J., Elliot, G., and Omodei, M. (2011). Issues in Community Bushfire Safety: Analyses of Interviews conducted by the 2009 Victorian Bushfires Research Task Force. Bushfire CRC. Report No. 4.

Nadimpalli, K. (2009). National Exposure Information System (NEXIS) - A capability for evidence based disaster management. In Proceedings of the 7th FIG Regional Conference, Vietnam, 19-22 October. http://www.fig.net/pub/vietnam/papers/ts05a/ts05a_nadimpalli_3658.pdf, accessed in July 2013.

Raj, P. (2008). A review of the criteria for people exposure to radiant heat flux from fires. J. of Hazardous Materials. Vol. 169 , issue $1,61-71$.

Solangaarachchi, D., Griffin, A.L., and Doherty, M.D. (2012). Social vulnerability in the context of bushfire risk at the urban-bush interface in Sydney: a case study of the Blue Mountains and Ku-ring-gai local council areas. Nat. Hazards 64:1873-1808.

Zhao, L., and Beck, V.R. (1997). The Definition of Scenarios for the CESARE-Risk Model. Proc. of the $5^{\text {th }}$ Int. Symposium on fire safety science. Melbourne. March 1997. 